\title{
Geo-location of Oncological Diseases in the Extra-urban Areas of Naples and Creation of Territorial Biobanks: An Important Tool to Study Potential Connections Between Environmental Factors and Cancer
}

\author{
MARGHERITA CERRONE, MONICA CANTILE, ORNELLA SACCO and GERARDO BOTTI \\ Pathology Unit, Istituto Nazionale Tumori Fondazione G. Pascale-IRCCS, Naples, Italy
}

\begin{abstract}
Many areas of the Campania region of Italy are more frequently at risk of neoplastic diseases due to environmental factors. However, the results of epidemiological studies, although numerous and detailed, do not explain tumor pathogenesis mechanisms in relation to the contribution of exposure to environmental pollutants. The Oncological Biobank of the G. Pascale Foundation (BBI) centralizes the collection and storage of biomaterials, both healthy and pathological human tissues, from urban and extra-urban areas of Naples, associating them with clinicopathological characteristics (type of tumor, histological type, grading, immunohistochemical and molecular profile, etc.). Geo-location of tumor samples is made by an IT platform in which demographic and clinical data are systematically uploaded. For the extra-urban areas of Naples, our experience of tumor sample geolocation highlighted cancer types with high impact of environmental pollutants as being lung, gastric and bladder cancer. In this mini-review, we underline that the possibility of specifically selecting tumor samples in circumscribed territories may allow targeted studies to verify potential connections between environmental factors and cancer. Moreover, the collection of biological fluids (serum, saliva, urine) from healthy individuals from specific areas may be a useful tool for the research of specific genetic polymorphisms linked to individual susceptibility.
\end{abstract}

It is well reported that several areas of southern Italy, particularly in the Campania region, are more frequently affected by certain types of cancer compared to other Italian

Correspondence to: Monica Cantile, Pathology Unit, Istituto Nazionale Tumori Fondazione 'G. Pascale', via Mariano Semmola, 803 Naples, Italy. Tel: +39 08590347; Fax: +39 08590378, e-mail: m.cantile@istitutotumori.na.it

Key Words: Geo-location, biobank, environmental factors and tumor diseases, review. regions (1-4). During the past three decades, large areas of Naples county have been extensively contaminated by environmental toxic agents, in particular for the presence of many landfills of industrial wastes. This region was already defined in the report of the World Health Organization in 1997 as one of the geographical areas most at risk of neoplastic diseases due environmental factors (5).

Thereafter, even prestigious international journals coined the term 'Triangle of Death' referring to the eastern area of the Campania region (6).

The term 'Land of Fires' was used for the first time in 2003 in a report by Legambient to indicate the provinces between Naples and Caserta as being areas with increased cancer mortality (7). Currently about 80 municipalities of the Campania region fall into the 'Land of Fires'.

However, the data on cancer prevalence, incidence and mortality in this region are very confused and fragmentary due to the incompleteness and inadequacy of a real cancer register in the Southern regions $(8,9)$. Over time, several geographical studies have precisely pointed out the areas with a higher cancer risk, the type of oncological disease and a detailed analysis of the type of pollutant exposure (10-14).

Based on these observations, the Italian National Health Service identified five main macro-areas in the Campania region, even if most of the municipalities remains stratified in extra-urban area of Naples, more precisely between Naples and Caserta. In these areas, death from neoplastic diseases is primarily associated with lung, digestive tract, genitourinary and soft-tissue tumors $(15,16)$.

The results of epidemiological studies, although numerous and detailed, do not provide specific information related to the pathogenesis of these tumors. In multifactorial diseases, the influence of other risk factors may have a synergistic effect with exposure to environmental pollutants. Therefore, in order to define appropriate strategies for a targeted prevention, knowledge of gene-environment interaction in particular areas is essential $(17,18)$. 
The advent of new molecular analysis technologies, including microarray-based genotyping and high-throughput next-generation sequencing allows the identification of several markers of susceptibility to tumor pathogenesis in populations from specific geographical areas (19). For these studies, one of the main problems is the spurious associations between genetic variants and disease caused by the structure of the population selected for the study. Sick individuals, as well as the control population should be stratified not only by age and sex, but also in relation to geographical area of origin, where the contribution of environmental factors might be different.

\section{Geo-location of Tumor Diseases}

The Oncological Biobank (BBI) of the G. Pascale Foundation (http://www.istitutotumori.na.it/RicercaScientifica/Biobanca.ht $\mathrm{ml}$ ), operative since 2005 , centralizes the collection, storage and conservation of biomaterials, both healthy and pathological human tissues, from urban and extra-urban areas of Naples. The BBI is part of the Pathology Unit, which in turn performs routine histomorphological diagnosis associated with the analysis of biomarkers with prognostic significance or predictive of therapeutic response, through the optimization of in situ (immunohistochemistry) and molecular (sequencing, etc.) analyses.

In recent years, the BBI has been associated with the diagnostic database developed by an IT platform (Telepat) that allows data from the management system to be imported and remodeled, creating a database useful for generating case studies and statistics of cytohistological samples for diagnostic and research studies. All information on collected biomaterials (type of tumor, histological type, grading, immunohistochemical and molecular profile, etc.) are systematically uploaded on the platform, which normalizes demographic and clinical data with those coming from different analytical methods. This allows: i) The geo-location of the BBI biomaterials (tissue samples), thereby defining a territorial stratification of the risk areas. ii) The identification of the most frequent genetic alterations obtained by new 'omics' analytical methods and highlight the molecular variants identified for optimal therapeutic stratification of patients with cancer. iii) Adoption of an integrated approach, combining epidemiology with molecular biology, making it possible to identify frequent and rare pathologies in specific geographical areas and suggesting specific screening on the territory.

\section{Examples of the Most Representative Tumors in Extra-urban Areas of Naples}

According to a recent estimate, the number of samples stored in the BBI from 2008 to 2016 would amount to about 40,475 samples.
Considering the geolocation of tumor samples collected in the BBI, in areas with high impact of environmental pollutants, the IT Telepat platform focused our interest in particular on three tumor types, lung, gastric and bladder cancer. These lesions are the most frequent in the 'Land of Fire' territory (see Figure 1). In detail, a total of 1,400 lung tumor samples were collected in the BBI in the past 5 years, of which more than $50 \%$ were concentrated in some areas of 'Land of Fire'. The same trend was highlighted for gastric cancer $(56 \%)$ and for bladder cancer (40\%). Other tumor types were heterogeneously distributed across the territory as shown in Figure 1.

The malignancies were located mainly in five macro-areas within the 'Land of Fires' as shown in Figure 2. The five identified areas are: Agro-aversano, Giugliano and surrounding areas, the shoreline Domitio-flegreo, the axis of the 'Triangle of Death' (Acerra-Nola-Marigliano), and a group of municipalities in the Caserta province. The municipalities included in these areas are highlighted in Figure 2.

Based on the available epidemiological and molecular evidence, the International Agency for Research on Cancer recently classified air pollution as 'Carcinogenic to Humans' (20). In particular, the strong relation between long-term exposure to air pollution and lung cancer risk has been abundantly described (21), while there are still few studies relating pollution to bladder cancer risk (23).

Recently, the association of long-term exposure to ambient air pollution with incidence of gastric cancer in 11 European cohorts was also investigated, showing that higher estimated risk of gastric cancer is related to particulate matter (PM2.5), mainly in men (24).

Therefore, our observations are in line with the reports from the literature, but the possibility of specifically selecting lesions according to geolocation would certainly offer the possibility of carrying out targeted studies to verify not only any direct connection between environment and cancer, but also for the identification of specific biomarkers implicated in tumor pathogenic processes. Moreover, the possibility of collecting biological fluids (serum, saliva, urine) suggests the enrollment of healthy individuals for the research of specific genetic polymorphisms linked to individual susceptibility.

\section{Creation of a Network of Biobanks}

The availability of selected high-quality biomaterials to perform gene-environment studies in specific geographic areas is an important premise. Furthermore, the definition of precision medicine for patients with cancer through the use of analytical platforms based on the 'omics" disciplines cannot deny the usability of high-quality biological samples, collected and stored in accordance with standardized procedures, regulated by Biobanks accredited at national and international levels (25). In fact, the main limitations in the use of these technologies are often associated with the poor quality of archived biomaterials, 


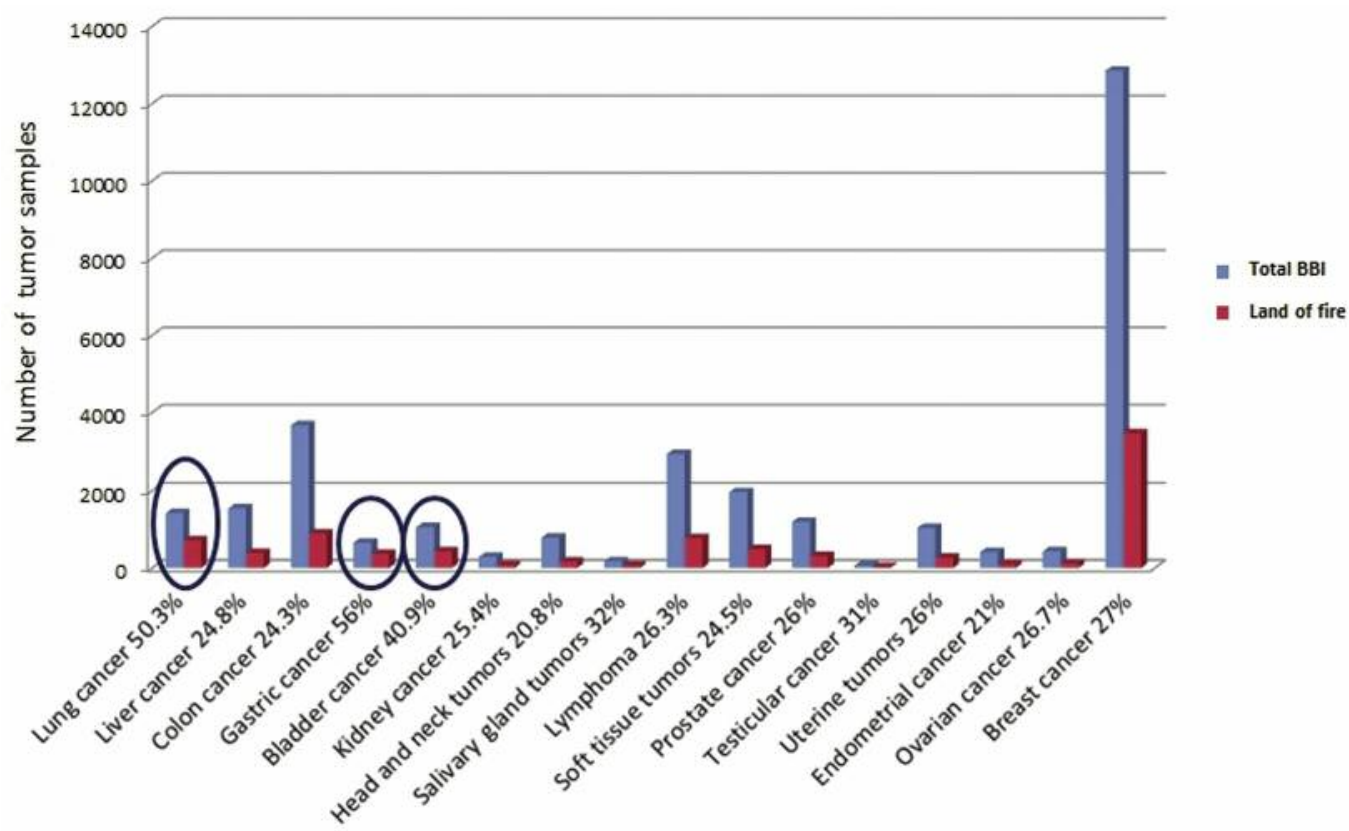

Figure 1. Distribution of samples from the Oncological Biobank (BBI) by tumor type in the past 5 years. Tumor types for the whole BBI and for the 'Land of Fires' are shown. Numbers represent cases in the 'Land of Fires' as a percentage of BBI cases for that tumor type. The most common tumor types in the 'Land of Fires' (red column) are: Lung, gastric and bladder cancer (50.3\%, 56\% and 40.9\% of total tumors, respectively). The other tumor types from the 'Land of Fires' account for about 24-32\% of all samples collected in the BBI.
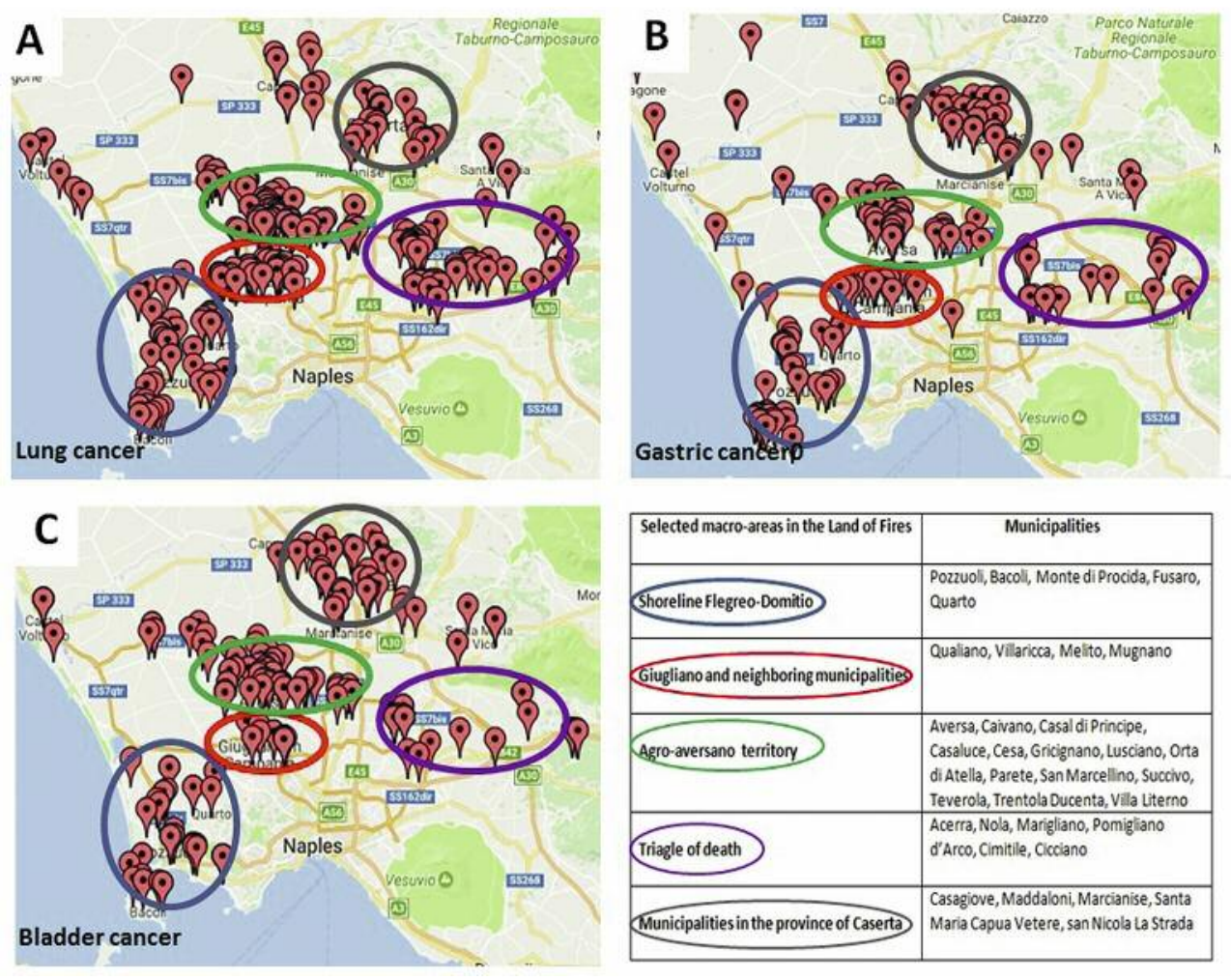

Figure 2. Geo-location of samples from the Oncological Biobank (BBI) in the 'Land of Fires' in the past 5 years. A: Lung cancer. Homogeneous distribution in all five macro-areas with more clustering along the Flegreo-Domitio shoreline, in municipalities neighboring Giugliano, in Agro-aversano and in the 'Triangle of Death'. B: Gastric cancer. Heterogeneous distribution, most represented in municipalities neighboring Giugliano, in Agroaversano, and in the province of Caserta. C: Bladder cancer. Heterogeneous distribution most represented in Agro-aversano, and in the province of Caserta. 
attributable in particular to RNA degradation (26-28). As a consequence, 'bio-banking' has become a dynamic discipline, contemplated by both public and private institutions focusing on translational oncology research (29).

The creation of regional biobanks able to collect and appropriately conserve large amounts of biomaterials, both biological tissues and liquids, such as blood, urine and saliva, is therefore an important target, especially in regions where areas strongly exposed to environmental pollutants may be present. The correct management of such collection should include the creation of a biobanks network to allow strategic coverage of the entire territory.

In the next year, for the collection of biomaterials and strategic coverage of the entire Campania region, in addition to the BBI, associated with the Naples county, regional health units will be enrolled as secondary biobanks. They will transfer the biomaterials to the central biobank in pre-defined times. The collected biomaterials will be represented by tissue and cytological samples, whole blood, plasma/serum, urine or other biological fluids (sputum, ascites, pleural fluids, etc.) from both patients with cancer and healthy individuals involved in screening projects.

\section{Conclusion}

The systematic collection of biological samples, with the implementation of biobanking and the creation of a Regional Network of Biobanks, will not only provide a consistent mapping of distribution of neoplastic diseases in the region, but also provide centralized information associated with the samples, a service of fundamental utility for population screening and to develop targeted translational research in oncology mainly orientated to knowledge of the pathogenic action of environmental pollutants in cancer development (30).

In addition, geo-location of tumor diseases and the creation of territorial biobanks will allow: i) The possibility of identifying specific molecular alterations in patients with cancer, enabling their enrollment in ad hoc clinical trials, and identifying alternative therapeutic opportunities for rare diseases or those resistant to standard therapies. ii) The identification of new bio-markers associated with carcinogenesis and tumor progression using biological fluids as a useful tool for early diagnosis. iii) The identification of markers of tumor susceptibility linked also to regional origin and lifestyle habits (e.g. polymorphic variants, still poorly known, of metabolism genes) for optimal monitoring of the population in specific areas 'at risk' for cancer.

\section{Acknowledgements}

This study was supported by the Italian Ministry of Health and by the Institutional Biobank (BBI) of the G. Pascale Foundation, National Tumor Institute.

\section{References}

1 Fazzo L, Belli S, Minichilli F, Mitis F, Santoro M, Martina L, Pizzuti R, Comba P, Martuzzi M, Bianchi F, Working Group: Cluster analysis of mortality and malformations in the provinces of Naples and Caserta (Campania Region). Ann Ist Super Sanita 44: 99-111, 2008.

2 Martuzzi M, Mitis F, Bianchi F, Minichilli F, Comba P and Fazzo L: Cancer mortality and congenital anomalies in a region of Italy with intense environmental pressure due to waste. Occup Environ Med 66: 725-732, 2009.

3 Fazzo L, De Santis M, Mitis F, Benedetti M, Martuzzi M, Comba P and Fusco M: Ecological studies of cancer incidence in an area interested by dumping waste sites in Campania (Italy). Ann Ist Super Sanita 47: 181-191, 2011.

4 Pizzi C, Arpino G, Acampora G, Aiello N, De Rosa A, Diaferia I, DI Nunzio A, Fragna G, Franco A, Russo M, Sansone F, Scarpati C, Spinuso A, Arpino G, Luce A, Tommasielli G, Caraglia $\mathrm{M}$ and De Placido S: Cancer prevalence in the city of Naples: Contribution of the GP database analyses to the cancer registries network. Mol Clin Oncol 1: 726-732, 2013.

5 The World Health Report 1997- conquering suffering, enriching humanity. World Health Forum 18: 248-260, 1997.

6 Senior C and Mazza A: Italian 'Triangle of Death' linked to waste crisis. Lancet Oncol 5: 525-527, 2004.

7 Rapporto Ecomafie. 9.1.3. 2003.

8 De Angelis R, Grande E, Inghelmann R, Francisci S, Micheli A, Baili P, Meneghini E, Capocaccia R and Verdecchia A: Cancer prevalence estimates in Italy from 1970 to 2010. Tumori 93: 392-397, 2007.

9 Crocetti E, Buzzoni C, AIRTUM Working Group: Italy is one of the European countries with the greatest population observed by cancer registries. Epidemiol Prev 34: 82, 2010.

10 Fusco M, Pezzi A, Benatti P, Roncucci L, Chiodini P, Di Maio G, Di Napoli R and de Leon MP: Clinical features and colorectal cancer survival: an attempt to explain differences between two different Italian regions. Eur J Cancer 46: 142-149, 2010.

11 Pirastu R, Zona A, Ancona C, Bruno C, Fano V, Fazzo L, Iavarone I, Minichilli F, Mitis F, Pasetto R and Comba P: Mortality results in SENTIERI Project. Epidemiol Prev 35: 29$152,2011$.

12 Barba M, Mazza A, Guerriero C, Di Maio M, Romeo F, Maranta P, Marino IR, Paggi MG and Giordano A: Wasting lives: the effects of toxic waste exposure on health. The case of Campania, Southern Italy. Cancer Biol Ther 12: 106-111, 2011.

13 Riccardi F, Nappi O, Balzano A, De Palma M, Buonerba C, Rizzo M, Barbato C, De Dominicis G, Buonocore U, De Sena G, Lastoria S, Molino C, Monaco G, Rabitti PG, Romano L, Scavuzzo F, Suozzo R, Uomo G, Volpe R, Di Lorenzo G and Carteni G: Neuroendocrine tumors diagnosed at the Antonio Cardarelli Hospital (Naples, Italy) between 2006-2009: A singleinstitution analysis. Int J Immunopathol Pharmacol 24: 251-256, 2011.

14 Rocco G, Petitti T, Martucci N, Piccirillo MC, LA Rocca A, LA Manna C, DE Luca G, Morabito A, Chirico A, Franco R, Accardo R, Normanno N, Botti G, Lodato S, Ciliberto G, Pedicini T and Giordano A: Survival after surgical treatment of lung cancer arising in the population exposed to illegal dumping of toxic waste in the Land of Fires ('Terra dei Fuochi') of Southern Italy. Anticancer Res 36(5): 2119-2224, 2016. 
15 Comba P, Ricci P, Iavarone I, Conti S, Bianchi F, Biggeri A, Fazzo L, Forastiere F, Martuzzi M, Musmeci L, Pasetto R, Pirastu R, Zona A and Crocetti E: SENTIERI Project: Rationale and objectives. Epidemiol Prev 38: 15-20, 2014.

16 Benedetti M, Fazzo L, Buzzoni C, Comba P, Magnani C and Fusco M: Incidence of soft-tissue sarcomas in an Italian area affected by illegal waste dumping sites. Arch Environ Occup Health 70: 154-159, 2015.

17 Rudolph A, Chang-Claude $J$ and Schmidt MK: Geneenvironment interaction and risk of breast cancer. Br J Cancer 114: 125-133, 2016.

18 Matejcic M and Iqbal Parker M: Gene-environment interactions in esophageal cancer. Crit Rev Clin Lab Sci 52: 211-231, 2015.

19 Jorge-Nebert LF, Jiang Z, Chakraborty R, Watson J, Jin L, McGarvey ST, Deka R and Nebert DW: Analysis of human CYP1A1 and CYP1A2 genes and their shared bidirectional promoter in eight world populations. Hum Mutat 31: 27-40, 2010.

20 Loomis D, Grosse Y, Lauby-Secretan B, El Ghissassi F, Bouvard V, Benbrahim-Tallaa L, Guha N, Baan R, Mattock H, Straif K; International Agency for Research on Cancer Monograph Working Group IARC: The carcinogenicity of outdoor air pollution. Lancet Oncol 14: 1262-1263, 2013.

21 Demetriou CA and Vineis P: Carcinogenicity of ambient air pollution: Use of biomarkers, lessons learnt and future directions. J Thorac Dis 7: 67-95, 2015.

22 Santibáñez-Andrade M, Quezada-Maldonado EM, OsornioVargas Á, Sánchez-Pérez Y and García-Cuellar CM: Air pollution and genomic instability: The role of particulate matter in lung carcinogenesis. Environ Pollut 229: 412-422, 2017.

23 Collarile P, Bidoli E, Barbone F, Zanier L, Del Zotto S, Fuser S, Stel F, Panato C, Gallai I and Serraino D: Residence in proximity of a coal-oil-fired thermal power plant and risk of lung and bladder cancer in north-eastern Italy. A populationbased study: 1995-2009. Int J Environ Res Public Health 14: 860-871, 2017.

24 Nagel G, Stafoggia M, Pedersen M, Andersen ZJ, Galassi C, Munkenast J, Jaensch A, Sommar J, Forsberg B, Olsson D, Oftedal B, Krog NH, Aamodt G, Pyko A, Pershagen G, Korek M, De Faire U, Pedersen NL, Östenson CG, Fratiglioni L, Sørensen M, Tjønneland A, Peeters PH, Bueno-de-Mesquita B,
Vermeulen R, Eeftens M, Plusquin M, Key TJ, Concin H, Lang A, Wang M, Tsai MY, Grioni S, Marcon A, Krogh V, Ricceri F, Sacerdote C, Ranzi A, Cesaroni G, Forastiere F, Tamayo-Uria I, Amiano P, Dorronsoro M, de Hoogh K, Beelen R, Vineis P, Brunekreef B, Hoek G, Raaschou-Nielsen O and Weinmayr G: Air pollution and incidence of cancers of the stomach and the upper aerodigestive tract in the European Study of Cohorts for Air Pollution Effects (ESCAPE). Int J Cancer 143: 1632-1643, 2018.

25 Lewis C, McQuaid S, Hamilton PW, Salto-Tellez M, McArt D and James JA: Building a 'Repository of Science': The importance of integrating biobanks within molecular pathology programmes. Eur J Cancer 67: 191-199, 2016.

26 Fedorowicz G, Guerrero S, Wu TD and Modrusan Z: Microarray analysis of RNA extracted from formalin-fixed, paraffinembedded and matched fresh-frozen ovarian adenocarcinomas. BMC Med Genomics 2: 23, 2009.

27 Kibriya MG, Jasmine F, Roy S, Paul-Brutus RM, Argos M and Ahsan H: Analyses and interpretation of whole-genome gene expression from formalin-fixed paraffin-embedded tissue: an illustration with breast cancer tissues. BMC Genomics 11: 622, 2010.

28 Abdueva D, Wing M, Schaub B, Triche T and Davicioni E: Quantitative expression profiling in formalin-fixed paraffinembedded samples by Affymetrix microarrays. J Mol Diagn 12: 409-417, 2010.

29 Botti G, De Cecio R and Cantile M: Tumor biobank as fundamental bio-resource for RNA analysis technologies. Minerva Biotecnologica 29: 106-107, 2017.

30 Botti G, Franco R, Cantile M, Ciliberto G and Ascierto PA: Tumor biobanks in translational medicine. J Transl Med 10: 204, 2012.
Received September 10, 2018

Revised September 26, 2018 Accepted October 1, 2018 